\title{
Introduction to the special section "Food Trade Relations of the Middle East and North Africa with Countries of the Tropics: Opportunities and Risks of South-South Cooperation"
}

\author{
Jordi Bacaria $^{1}$ • Karim El Aynaoui ${ }^{2}$. Eckart Woertz ${ }^{1}$
}

Received: 21 September 2015 / Accepted: 22 September 2015 / Published online: 19 October 2015

(C) Springer Science+Business Media Dordrecht and International Society for Plant Pathology 2015

We are very pleased to present this special section in Food Security. Its papers were first presented at the conference "Tropical Agriculture as 'Last Frontier'? Food Import Needs of the Middle East and North Africa, Ecological Risks and New Dimensions of South-South Cooperation with Africa, Latin America and South-East Asia." The conference was jointly held in Barcelona on 29-30 January 2015 together with our co-organizers, King's College, London (KCL), the Getulyo Vargas Foundation in Sao Paolo and Wageningen University.

The special section is one of the latest products of the strategic partnership between CIDOB, the Barcelona Center for International Relations, and the OCP Policy Center in Rabat, a partnership that has been effective since 2010. Both institutions have embarked on a joint project on food security and agriculture, covering key areas such as food politics, tropical "agriculturalization", climate change mitigation, development cooperation, as well as socio-cultural, institutional and gender aspects of water and food security. The choice of these topics is testimony to the importance our partners attribute to agriculture and food security as strategic fields as well as game changers in development discourse and practice.

The Middle East and North Africa (MENA) region is not only the largest oil exporter of the world, it is also its largest food importer. This import dependence will grow, given limited water and land resources on the supply side and population growth and more diversified diets on the demand side. In

Eckart Woertz

ewoertz@cidob.org

1 CIDOB (Barcelona Centre for International Affairs), Barcelona, Spain

2 OCP Policy Center, Rabat, Morocco contrast to earlier food regimes, an increasing share of the MENA's staple food imports such as corn, soybeans, palm oil, poultry, rice and sugar comes from tropical countries such as Brazil and Indonesia, where dramatic agricultural expansion has taken place. Other tropical regions such as SubSaharan Africa have looked to emulate such agricultural experiences, which are often based on large-scale and input intensive farming models. While such expansion processes have increased trade options of major importers such as the MENA, China and Japan, they have also had questionable ecological and socio-economic implications in the respective tropical countries.

Against this backdrop Eckart Woertz and Martin Keulertz set the scene in the opening article by analyzing food trade patterns of the MENA and the relative importance that tropical countries play in MENA food supplies. Their trade contribution has changed over different food regimes and now encompasses staple foods such as corn, rice and soybeans beside classical tropical export commodities. Woertz and Keulertz also discuss agricultural investment flows from the MENA to the tropics, associated political and socio-economic issues, a pronounced implementation gap of such investments and how they relate to MENA food security strategies. One of their conclusions is that food trading houses, storage strategies and brownfield investments in developed agro markets are more important as a trend than the widely publicized intention to acquire land in greenfield projects in developing countries.

Michael Gilmont identifies food trade and "water resource decoupling" in the MENA as a mechanism for circumventing national water scarcity. The OECD has described the concept of decoupling as "breaking the link between 'environmental bads' and 'economic goods"'. Gilmont models how MENA countries can considerably reduce the environmental impact of economic growth by outsourcing the production of water intensive crops. 
Using global spatial datasets Mark Mulligan builds scenarios for tropical agriculturalization and analyzes how they might affect forests, protected areas and biodiversity. He examines land use change and ecological risk factors and identifies which non-agricultural lands might be best suited for agricultural expansion. After discussing probabilities and uncertainties of climate change models, he outlines how climate change might affect supply chains and therefore food supplies from tropical regions to the MENA.

The following articles deal with agriculture in tropical countries and the impact of commercial farming. The Brazilian model of agricultural expansion and food security interventions plays a prominent role in three of these articles. Brazil has seen a steep rise in agricultural production and food trade in recent decades. It has also sought to export aspects of its farming model to Africa via South-South development cooperation.

Gabriela Marcondes and Tom de Bruyn analyze food security interventions of Brazil's Zero Hunger program and attempts to replicate them in African development cooperation, most notably in Mozambique and Malawi. The Zero Hunger program that the Lula administration launched in the 2000s has encompassed conditional cash transfers (Bolsa Familia), school meals and other nutrition interventions, income generation, social safety nets and strengthening of family farms. It has led to a measurable decrease of hunger in the country and has been lauded internationally. However, inequality of income and land ownership in Brazil remains stubbornly high. The authors analyze how agricultural development cooperation fits into Brazil's overall approach towards South-South cooperation and how it differs from traditional donor countries and agencies.

Vanessa Empinotti analyzes land tenure and shows how the opening of the Brazilian cerrado savannah to soybean farming cannot be seen in pure dichotomies of small-scale vs. largescale farming. Beside great latifundia estates there are smaller entrepreneur and family farming operations. Former smallholders from the south of the country who have moved to the cerrado have been able to increase their holdings and improve their livelihoods.

Jeroen Warner takes a critical stance towards Brazil's South-South cooperation and analyzes its geopolitical implications. He cautions against overt optimism about such cooperation as being anti-colonialist and a benign alternative to cooperation with developed countries. South-South cooperation is not egalitarian he argues, but often driven by regional hegemons such as Brazil, which is investor and investee alike in a global push towards acquisitions of farmland and resources. The state is a driving force in this development, often via public private partnerships. The equally involved transnational corporations have not superseded it yet as prime mover.
Unlike Brazil, Peru is not a major food exporter to the MENA, yet Juana Vera Delgado's analysis of the Water Transfer Agribusiness (WATA) model in Peru carries important lessons for agricultural expansion in other tropical regions. The WATA approach increased agricultural production via largescale irrigation schemes and diversion of water from the highlands to arid coastal areas. At the same time it led to heightened vulnerabilities of environment, climate, poorer classes and women.

Turning to Africa, Timothy Olalekan Williams showcases several examples of foreign direct investments in African agriculture and analyzes reasons for their failure or lack of full implementation. Inadequate understanding of the social and institutional milieu in the host country, poor assessment of the biophysical status of leased land, inappropriate business models and political instability have been among the problems. Yet he argues that largescale commercial agriculture is feasible in Africa and can co-exist with smallholder agriculture if social and environmental impacts are managed and business models and business environments are overhauled.

This special section collects the revised and updated versions of eight conference papers of authors from Purdue University, CIDOB, University of Oxford, King's College, London, University of Antwerp, Katholieke Universiteit Leuven, Universidade Federal do ABC, Wageningen University and the International Water Management Institute (IWMI). We wish to thank all the experts who took part in the conference for their valuable contributions and analytical insights. This publication would not have been possible without their hard work, as well as the concerted effort of all parties involved.

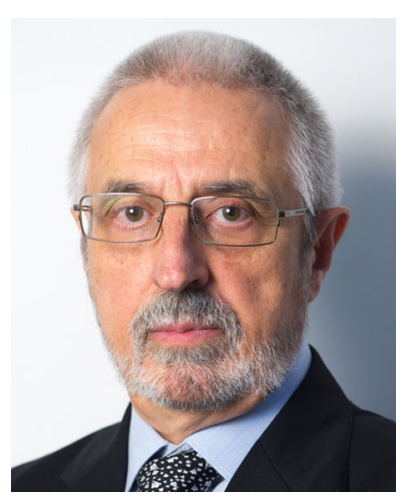

Jordi Bacaria is Director of CIDOB (Barcelona Centre for International Affairs) and Professor of Applied Economics at the Autonomous University of Barcelona (UAB), where he was dean of the Faculty of Economics (19861988), director of the Institute for European Studies (1988-1992, 1994-2000) and coordinator of the Doctoral Program in International Relations and European Integration (2000-2009). He is also director of the journal "Foreign Affairs Latinoamérica" published in Mexico and a member of FEMISE (Euro-Mediterranean Forum of Economic Science Institutes). From 2000 to 2013, he was co-director of the Institute for European Integration Studies in Mexico, an institution 
funded by the European Commission and the Autonomous Technological Institute of Mexico. He is the author of over a hundred publications (articles, book chapters and books) on economic integration, Latin America, Mediterranean economy, monetary institutions and public choice.

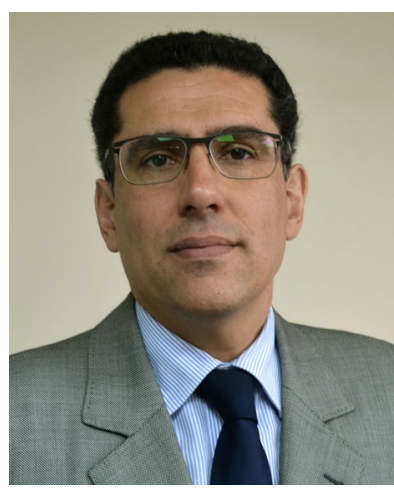

Karim El Aynaoui is currently Managing Director of OCP Policy Center, and advisor to the CEO and Chairman of OCP, a global leader in the phosphate sector. From 2005 to 2012 he worked at Bank Al-Maghrib, the Central Bank of Morocco. He was the Director of Economics and International Relations, where he provided strategic leadership in defining and supporting monetary policy analysis and strategy. He was also in charge of the Statistical and International Relations Divisions of the Central Bank, led the research division and was a member of the Governor's Cabinet. Before joining Bank Al-Maghrib, Karim El Aynaoui worked for eight years at the World Bank, both in its Middle Eastern and
North Africa, and Africa regions as an economist. He holds a $\mathrm{PhD}$ in economics from the University of Bordeaux, where he taught for three years. He has published articles in scientific journals on macroeconomic issues in developing countries.

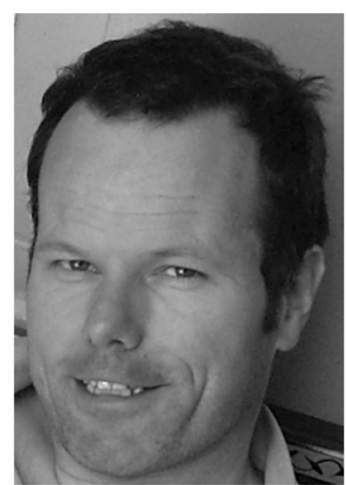

Eckart Woertz is a senior research fellow at CIDOB, the Barcelona Centre for International Affairs. Formerly he was a visiting fellow at Princeton University, director of economic studies at the Gulf Research Center (GRC) in Dubai and worked for banks in Germany and the United Arab Emirates. He teaches at the Barcelona Institute of International Studies (IBEI), was KSP visiting professor at the Paris School of International Affairs (PSIA) at SciencesPo and holds a PhD in economics from Friedrich-Alexander University, Erlangen-Nuremberg. He is author of Oil for Food (Oxford University Press 2013) and editor of GCC Financial Markets (Gerlach Press 2012). 